\title{
Extremely high concentration of folates in premature newborns
}

\author{
Zikavska T, Brucknerova I \\ 1st Department of Paediatrics, Faculty of Medicine, University Hospital, Comenius University, Bratislava, \\ Slovakia.zikavska@gmail.com
}

\begin{abstract}
Objectives: Extremely high concentration of folates in premature newborns: case reports.
Background: Folates are a group of water soluble compounds, which are important for metabolic processes in human body. These are important during periods of rapid cell growth. The most accurate indicator of long-term folate level status in the body is the determination of red blood cell (RBC) folate concentrations. The optimal level of RBC folate is not known in neonatal period. Authors discuss the reasons for extremely high level of RBC folate concentrations.

Methods: In our work we present the cases of two premature newborns with extremely high level of RBC folate concentrations, which were analyzed immunochemically on the first day of life and after six weeks of life. Results: In both cases we measured RBC folate concentrations on the 1st day of life. After 6 weeks we found extremely high RBC folate concentration level $(5516.67 \mathrm{ng} / \mathrm{ml})$ in the first case after RBC transfusions. In second case after two months of life the RBC folate concentration level was doubled $(2335.1 \mathrm{ng} / \mathrm{ml})$ until 24 hours after RBC transfusion compared to levels after birth.

Conclusion: The normal range of RBC folate values vary in newborns. The upper limit of daily dose of folic acid in pregnancy and neonatal period is not known. On the other hand it is an easily excreted water-soluble vitamin but in premature newborn it can lead to the disruption of metabolic balance and slow its degradation. Some factors can have an impact on RBC folate concentration. Blood transfusion can be one of the main influences on RBC folate concentration. To clarify these mechanisms further studies are required (Ref. 29). Text in PDF www.elis.sk.

Key words: newborn, folic acid, anaemia, red blood cell folate concentrations, blood transfusion.
\end{abstract}

\begin{abstract}
Abbreviations: $\mathrm{RBC}$ - red blood cell, NTD - neural tube defects, MTHFR - methylenetetrahydrofolate reductase, MTRR - methionine synthase reductase
\end{abstract}

Folates participate in multiple different biochemical pathways and their metabolism intersects on an important step in onecarbon metabolism. Folate with choline are required in period of neurogenesis in brain and spinal cord (1). For healthy embryonic growth the optimal folate status in cells is needed to secure optimal deoxyribonucleic acid methylation status (2). Interference of abnormal metabolism in the pathogenesis of neural tube defects and neurological and vascular diseases has been elucidated (3). The benefits of folic acid supplementation in decreasing the risk of neural tube defects (NTD) have been published (4). Folic acid supplementation during early pregnancy was associated with a

1st Department of Paediatrics, Faculty of Medicine, University Hospital, Comenius University, Bratislava, Slovakia

Address for correspondence: T. Zikavska, MD, 1st Department of Paediatrics, Faculty of Medicine, University Hospital, Comenius University, Limbova 1, SK-833 40, Bratislava, Slovakia.

Phone: +421.911148447

Acknowledgements: We would like to thank for measurement of red blood cell folate concentration levels to our colleagues from the Department of Clinical Biochemistry in the Children's Hospital in Bratislava, Slovakia, mainly Darina Behulova, M. D., Ph. D. and Alena Vasilenkova, D.Sc. This work was supported by a grant from the Comenius University (GUK 376/2012). decreased risk of cleft lip (5). There was also lower prevalence in some regions in Slovakia. The frequency of the risk rate of a birth of a child with orofacial clefts was 1 in 671 live births in Western Slovakia (6). In comparison with the Czech Republic the overall incidence of cleft defects was 1 in 600 live births (7). Some research has reported a reducing risk of NTD by $50-70 \%$, but it is a necessity to identify the genetic risk factors of NTD. Many genetic variants have been identified, but only a few of these variants have been associated with NTD risk. Only two single-nucleotide polymorphism in genes (MTHFR C677T, MTRR A66G) are considered to be risk factors for NTD (8). The genetic polymorphisms of the MTHFR can be also associated with some neuropsychiatric disorders, such as major depressive disorders (9).

The importance of some nutrients (folic acid, alpha tocopherol, vitamin D and polyunsaturated fatty acids) during critical stages of pregnancy is currently recognized. The exposure to epigenetic changes is responsible for altering the mechanisms of growth and metabolism and it leads to changes that may persist throughout life causing increased susceptibility to disease. Some factors before and after birth can decrease levels of stress and mental illness (10). Important factor in prevention of cardiovascular diseases is an adequate nutrition which was recorded in reduction of hyperhomocysteinemia (11). The risk of stable ischemic heart disease increases due to hyperhomocysteinemia. In Slovak patients, very high prevalence of hyperhomocysteinemia was detected in patients with stable ischemic heart disease (12). 
103-106

Anaemia is defined as a hemoglobin concentration or erythrocytes mass less than 5 th percentile for age. Anaemia is usually classified based on the size of RBCs as measured by the mean corpuscular volume. The lack of folic acid leads to macrocytic anaemia (13). To prevent this state, one option is folic acid supplementation.

The indication for blood transfusion in newborns is still discussed. Each hospital has its own guidelines for neonatal packed $\mathrm{RBC}$ transfusions. Many indications for an RBC transfusion in neonates are based on the maintenance of a specific hematocrit level, replacement of phlebotomy losses or treating clinical symptoms of anaemia (apnoea, tachycardia, tachypnoea and growth failure) (14).

$\mathrm{RBC}$ transfusions ensure adequate tissue oxygenation during intensive care period or the treatment of clinically significant symptomatic anaemia in newborns (15). Experimental studies are essential for understanding the general mechanisms of blood transfusions. It is apparent that blood transfusions increase oxygencarrying capacity in tissues, while adequately restoring microvascular perfusion deficiency in anaemia (16). In human studies, it has been confirmed that the increasing number of transfusions given in the first 28 days of life remained significantly associated with hypoxaemia due to chronic lung disease (17).

\section{Method}

In this work we introduce the cases of two newborns with extremely high level of RBC folate concentrations. Their RBC folate concentrations levels were analyzed immunochemically on the first day of life and after six weeks of life. Blood samples for determining $\mathrm{RBC}$ folate were collected in vacutainers containing EDTA and taken to the Department of Clinical Biochemistry in Hospital for Children in Bratislava. Within 24 hours of collection full blood count analysis was undertaken. The lysing agent (1.5 $\mathrm{ml} 0.2 \%$ ascorbic acid) was added to $50 \mu \mathrm{l}$ of whole blood for the RBC folate analysis (Roche Diagnostics, Slovakia). Immunochemical analysis was performed with the use of chemiluminescent emission (analyser cobas e 411). It was based on a competitive test using natural folate binding protein specific for folate. Folate competes with the added folate for the binding sites of folate binding protein labeled with ruthenium complex.

The authors inform about variable limits in different ages, especially in neonatal period in the Slovak population. There were some factors which can influence on RBC folate concentrations.

\section{Results}

\section{Case report 1}

The authors present the case of a male newborn who was born by caesarean section in the 27 th week of gestation. Familiar history was negative. Birth weight was 900 grams and birth length was 29 centimeters. Immediately after birth he was atonic, with apnoea and acrocyanosis, but without bradycardia. The Apgar score was 5 points in the first minute and 8 points in the fifth minute after birth. During the first 10 weeks of life he overcame some complications of prematurity, such as respiratory distress syndrome and apnoea. At the beginning distance therapy was performed due to respiratory distress syndrome. The newborn was without support ventilation after 24 hours of life. In laboratory findings, after three weeks of life, anaemia of prematurity was recorded. This state was potentiated by sepsis. Due to this sepsis (Staphylococcus aureus) he obtained two transfusions of red blood cells according to the clinical state and laboratory tests. In the $9^{\text {th }}$ week of life the retinopathy of prematurity required diode laser retinal photocoagulation.

On the first day of life the blood samples for determining RBC folate were analyzed immunochemically. The RBC folate concentration level was $1214.04 \mathrm{ng} / \mathrm{ml}$. After six weeks of life we found extremely high RBC folate concentrations level of $5516.67 \mathrm{ng} / \mathrm{ml}$. At the same time mild anaemia was presented (haemoblobin 9.8 $\mathrm{g} / \mathrm{dl}$; erythrocytes $3.44 \times 10^{12} / 1$; haematocrit $27.9 \%$ ). Concentration of unconjugated bilirubin was within limits of standard scale.

\section{Case report 2}

The second case was a male newborn who was born by caesarean section in the 28th week of gestation. Birth weight was 1330 grams and birth length was 30 centimeters. Mild asphyxia occurred after birth. Apgar score was 6 points in the first minute and 7 points in the fifth minute after birth. During hospitalization he suffered from some complications of prematurity. The most interesting clinical finding was intraventricular haemorrhage and consequently hydrocephalus with surgery solution. The complication of this diagnosis was ventriculitis with the need for transfusion. In this case we also measured RBC folate concentration levels on the first day of life, which was $1306.5 \mathrm{ng} / \mathrm{ml}$. At 2 months of life and after receiving one blood transfusion an extremely high RBC folate concentration level of $2335.1 \mathrm{ng} / \mathrm{ml}$ was recorded. At the same time anaemia was present (haemoblobin $8.6 \mathrm{~g} / \mathrm{dl}$; erythrocytes $3.3 \times 10^{12} / 1$; haematocrit $26.1 \%$ ) and the concentration of unconjugated bilirubin was within limits of standard scale.

\section{Discussion}

Accurate indicator of body saturation by folic acid is the analysis of its concentration in erythrocytes. In contrast to folic acid levels in serum, which reflect daily changes in the body and the impact of diet, concentration of folates in erythrocytes is a reflection of long-term processes and reserves in the body.

Erythrocyte folate levels would be expected to decline more slowly than serum folate levels over the first six weeks of age in term newborns (18).

The requirement of periconceptual supplementation with folate was already documented. Risk factors associated with birth defects of central nervous system include deficiency of folate supplementation, cigarette smoking and exposure to x-rays (19). Currently the supplemental dose for pregnant woman is recommended at $0.4 \mathrm{mg}$ of folic acid daily (20). The influence of folic acid during pregnancy on the birth weight and risk of intrauterine growth retardation and NTD were observed in some studies $(4,8,21,22)$.

The red cell folate is the primary indicator to determine folate adequacy. Because folate is taken up only by the developing erythrocyte in the bone marrow and not by the circulating mature 
erythrocyte during its 120-day lifespan, erythrocyte folate concentration is an indicator of long-term status (23). Plasma folate concentration decreases markedly with age (24). It was observed in breastfed infants independent of maternal folate status that concentrations of folate decreases from birth until 24 months (25).

The normal RBC folate level is $150-600 \mathrm{ng} / \mathrm{ml}$ (26). Also Jyothi et al. published similar results of RBC folate concentration $(486-724 \mathrm{ng} / \mathrm{ml})$ by chemiluminescent microparticle immunoassay and no deficiency was found $(<140 \mathrm{ng} / \mathrm{ml})$ (27). In both our cases we measured RBC folate concentration on the first day of life within the limits of standard scale with our analytic methods (Roche diagnostics, analyser cobas e 411). In both cases we found extremely elevated levels in the second sample. Any other hemolyses in the body were not found, the levels of bilirubin were within the limits of standard scale.

After mandatory folic acid fortification, persistent circulating unmetabolised folic acid in Irish people was reported (28). In our first case the patient was fed with formula for premature newborns with recommended daily dose of folic acid $(50 \mu \mathrm{g} / \mathrm{kg})$. In the second case the child was fed with maternal milk or breastfed. We did not assume the nutrition was a reason for high level of RBC folate concentrations. Hay et al, 2008, published decreasing folates from birth until 24 months of life and positive correlation with duration of exclusive breastfeeding (25).

In both cases the important external factor for RBC folate levels was the administration of RBC transfusion. RBC transfusion has the potential to significantly influence tissue oxygen delivery (15). In many neonatal units RBC transfusions are administered daily but also have strict rules. The transfusions are based on a decision, taking into account the patients' clinical status. Risks concerning "old blood" are based on the age of transfusion. "Older blood" means blood stored for about 2 weeks that can have higher potassium content which can induce arrhythmias in the neonate (14). Other animal studies confirmed changed microvascular perfusion, which can modulate the entrance of RBC into capillaries and $\mathrm{RBC}$ deformability. A significant increase of chronic lung disease after repeated transfusions in preterm infants was reported (16). Also, blood transfusions are temporally related to necrotizing enterocolitis in preterm newborns, but more prospective studies are needed (29). However, it is a clinical observation that blood transfusions have irreplaceable beneficial effects on patient's energy levels, exercise tolerance and positive oxygenation effect for tissues due to increased blood viscosity, improving perfusion and functional capillary density, allowing oxygen delivery by the remaining erythrocytes and flushing out metabolites produced during hypo-perfusion (16).

\section{Conclusion}

RBC folate concentration is an accurate indicator of body saturation by folic acid. It is influenced by several factors on the mother's side (i. e. anaemia, chronic hypoxaemia due to cigarette smoking or low nutrition) as well as on the newborn's side and/or other associated complications as documented in this work. This work reported extremely high concentration levels of folate in two pre- mature newborns after many complications of prematurity and repeated $\mathrm{RBC}$ transfusions. The question remains how to explain the extremely high level of folate concentration levels after RBC transfusions. Some of these reasons are high tissue oxygenation and higher risk of tissue damage due to increased oxygen affinity and changes in functional capillary density and a high intake of micronutrients presented in RBC transfusions. Toxicity of folic acid is not a concern, as folate is water-soluble and easily excreted by kidneys when in excess; on the other hand the growing body of preterm newborn and disruption of metabolic balance could be a potential risk. The side effect of blood transfusion on extremely high level of RBC folate is not known in this area. More studies are necessary to determine this issue.

\section{References}

1. Zeisel SH. Importance of methyl donors during reproduction. Am J Clin Nutr 2009; 89: 673-677.

2. Kim K, Friso S, Choi S. DNA methylation, an epigenetic mechanism connecting folate to healthy embryonic development and aging. J Nutr Biochem 2009; 20 (12): 917-926.

3. Hoffbrand AV, Weir DG. Historical review. The history of folic acid. Br J Haematol 2001; 113: 579-589.

4. Banhidy F, Dakhlaoui A, Puho EH, Czeizel AE. Is there a reduction of congenital abnormalities in the offspring of diabetic pregnant women after folic acid supplementation? A population-based case-control study. Congenital Anomalies 2011; 51: 80-86.

5. Wilcox AJ, Lie RT, Solvoll K, Taylor J, McConnaughey DR, Abyholm F, Vindenes H, Vollset SE, Drevon CA. Folic acid supplements and risk of facial clefts: national population based case-control study. BMJ 2007; 335 (464): 1-6.

6. Fedeles J, Ziak P, Krizko M, Payer J, Bohac M, Palencar D, Hulin I, Fedeles J. Prevalence of cleft lip and palate in western Slovakia in the years 2001-2007. Bratis1 Med J 2012; 113 (2): 117-119.

7. Urbanova W, Kotova M, Vankova Z. The incidence of cleft lip and palate in the Czech Republic in 1994-2008. Bratisl Med J 2013; 114 (8): 474-479.

8. van der Linden IJ, Afman LA, Heil SG, Blom HJ. Genetic variation in genes of folate metabolism and neural-tube defect risk. Proc Nutrition Soc 2006; 65 (2): 204-215.

9. Evinova A, Babusikova E, Straka S, Ondrejka I, Lehotsky J. Analysis of genetic polymorphisms of brain-derived neurotrophic factor and methylenetetrahydrofolate reductase in depressed patients in a Slovak (Caucasian) population. Gen Physiol Biophys 2012; 31 (4): 415-422.

10. Capra L, Tezza G, Mazzei F, Boner AL. The origins of health and disease: the influence of maternal diseases and lifestyle during gestation. Ital J Pediatr 2013; 39: 1-7.

11. Madaric A, Kadrabova J, Krajcovicova-Kudlackova M, Valachovicova M, Spustova V, Mislanova C, Kajaba I, Blazicek P. The effect of bioactive complex of quercetin, selenium, catechins and curcumin on cardiovascular risk markers in healthy population after a two month consumption. Bratisl Med J 2013; 114 (2): 84-87.

12. Lietava J, Vohnout BB, Dukat A, Fodor GJ. Homocysteine Slovakia study: study design and occurrence of hyperhomocysteinaemia and other risk factors. Bratisl Med J 2012; 113 (2): 80-86. 
$103-106$

13. Janus J, Moerschel SK. Evaluation of anemia in children. Am Fam Physician 2010; 81 (12): 1462-1471.

14. Kasat K, Hendricks-Muñoz KD, Pradee VM. Neonatal red blood cell transfusions: searching for the better guidelines. Blood Transfus 2011; 9: 86-94.

15. Murray NA, Roberts IAG. Neonatal transfusion practice. Arch Dis Child Neonatal Ed 2004; 89: F101-F107.

16. Tsai AG, Hofmann A, Cabrales P, Intaglietta M. Perfusion vs. oxygen delivery in transfusion with "fresh" and "old" red blood cells: The experimental evidence. Transfus Apher Sci 2010; 43 (1): 69-78.

17. Cooke RWI, Drury JA, Yoxall CW, James C. Blood transfusion and chronic lung disease in preterm infants. Eur J Pediatr 1997; 156: 47-50.

18. Bjorke Monsen AL, Ueland PM, Vollset SE, Guttormsen AB, Markestad T, Solheim E, Refsum H. Determinants of cobalamin status in newborns. Pediatrics 2001; 108: 624-630.

19. Raza MZ, Sheikh A, Ahmed SS, Ali S, ANaqvi SMA. Risk factors associated with birth defects at a tertiary care center in Pakistan. Ital J Pediatr 2012; 38: 68.

20. WHO. Guideline: Daily iron and folic acid supplementation in pregnant woman. Geneva; World Health Organization, 2012.

21. Rondo PH, Tomkins AM. Folate and intrauterine growth retardation. Ann Trop Paediatr 2000; 20: 253-258.

22. Relton CL, Pearce MS, Parker L. The influence of erythrocyte folate and serum vitamin $B_{12}$ status on birth weight. Br J Nutr 2005; 93: 593-599.
23. Institute of Medicine, Food and Nutrition Board. Dietary reference intakes for thiamin, riboflavin, niacin, vitamin B6, folate, vitamin B12, pantothenic acid, biotin, and choline / a report of the Standing Committee on the Scientific Evaluation of Dietary Reference Intakes and its Panel on Folate, Other B Vitamnis, and Choline and Subcommittee on Upper Reference Levels of Nutrients, National Academy Press, Washington DC; 1998. ISBN 0309065542.

24. van Beynum IM, Heijer M, Thomas CMG, Afman L, Emmerzaal DO. Total homocysteine and its predictors in Dutch children. Am J Clin Nutr 2005; 81: 1110-1116.

25. Hay G, Johnston C, Whitelaw A, Trygg K, Refsum H. Folate and cobalamin status in relation to breastfeeding and weaning in healthy infants. Am J Clin Nutr 2008; 88 (1): 105-114.

26. Glader B. Anemias of inadequate production. 2006-2017. In: Kliegman RM. Nelson textbook of pediatrics. Philadelphia; Elsevier, 2007.

27. Jyothi S, Misra I, Morris G, Benton A, Griffin D, Allen S. Red cell folate and plasma homocysteine in preterm infants. Neonatology 2007; 92: 264-268.

28. Sweeney MR, Staines A, Daly L, Traynor A, Daly S, Bailey SW, Alverson PB, Ayling JE, Scott JM. Persistent circulating unmetabolised folic acid in a setting of liberal voluntary folic acid fortification. Implications for further mandatory fortification? BMC Public Health 2009; 9 (295): 1-7.

29. Singh R, Visintainer PF, Frantz ID, Shah BL, Meyer KM, Favila SA, Thomas MS, Kent DM. Association of necrotizing enterocolitis with anemia and packed red blood cell transfusions in preterm infants. J Perinatol 2011; 31: 176-182. 